Purdue University

Purdue e-Pubs

8-31-2007

\title{
Chemical kinetic considerations for postflame synthesis of carbon nanotubes in premixed flames using a support catalyst
}

Prarthana Gopinath

Jay P. Gore

gore@purdue.edu

Follow this and additional works at: http://docs.lib.purdue.edu/nanodocs

Gopinath, Prarthana and Gore, Jay P., "Chemical kinetic considerations for postflame synthesis of carbon nanotubes in premixed flames using a support catalyst" (2007). Other Nanotechnology Publications. Paper 60.

http://docs.lib.purdue.edu/nanodocs/60

This document has been made available through Purdue e-Pubs, a service of the Purdue University Libraries. Please contact epubs@purdue.edu for additional information. 
Provided for non-commercial research and education use. Not for reproduction, distribution or commercial use.

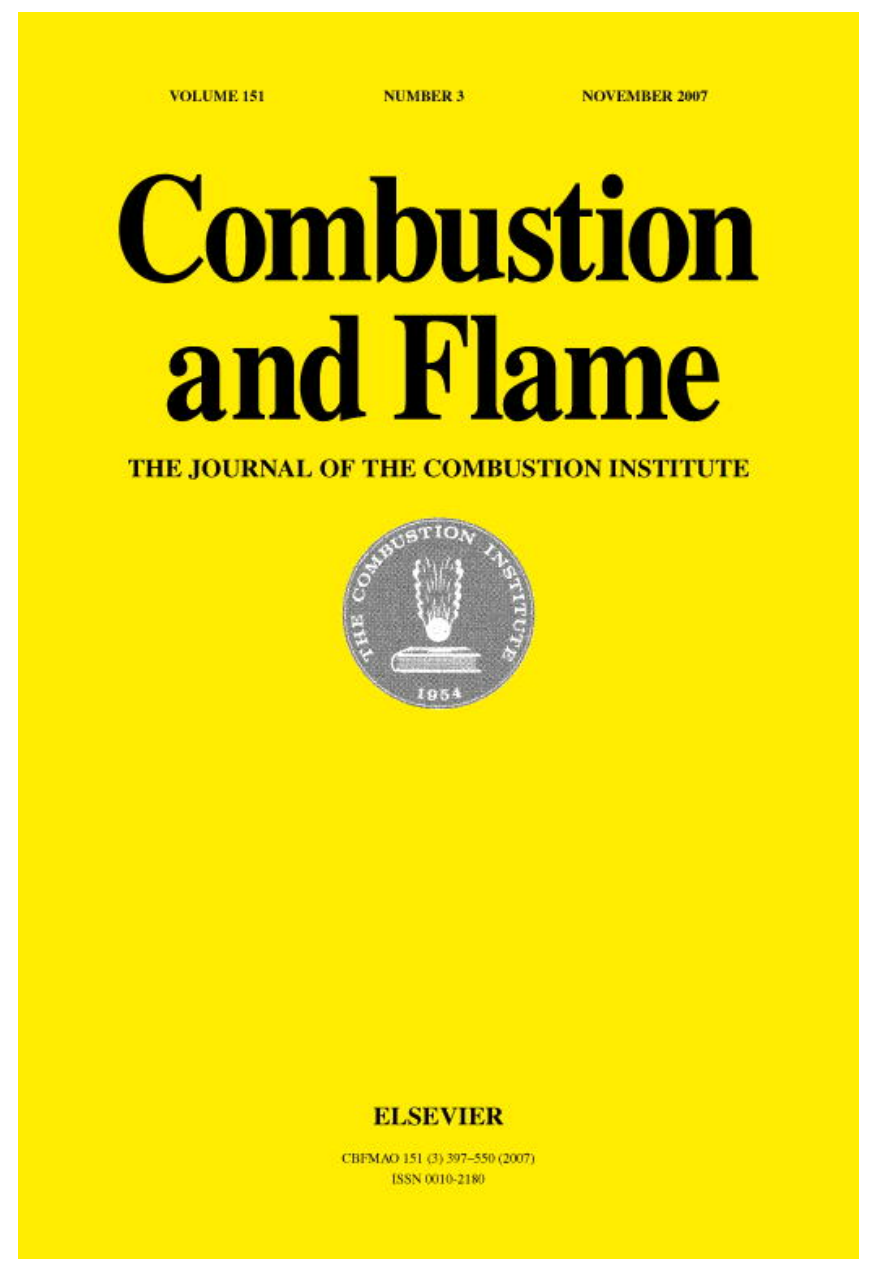

This article was published in an Elsevier journal. The attached copy

is furnished to the author for non-commercial research and education use, including for instruction at the author's institution, sharing with colleagues and providing to institution administration.

Other uses, including reproduction and distribution, or selling or licensing copies, or posting to personal, institutional or third party websites are prohibited.

In most cases authors are permitted to post their version of the article (e.g. in Word or Tex form) to their personal website or institutional repository. Authors requiring further information regarding Elsevier's archiving and manuscript policies are encouraged to visit: 


\title{
Chemical kinetic considerations for postflame synthesis of carbon nanotubes in premixed flames using a support catalyst
}

\author{
Prarthana Gopinath, Jay Gore* \\ School of Mechanical Engineering, Purdue University, West Lafayette, IN 47907, USA
}

Received 16 May 2004; received in revised form 10 May 2006; accepted 29 May 2006

Available online 31 August 2007

\begin{abstract}
Multiwalled carbon nanotubes (MWCNTs) on a grid supported cobalt nanocatalyst were grown, by exposing it to combustion gases from ethylene/air rich premixed flames. Ten equivalence ratios $(\phi)$ were investigated, as follows: 1.37, 1.44, 1.47, 1.50, 1.55, 1.57, 1.62, 1.75, 1.82, and 1.91. MWCNT growth could be observed for the range of equivalence ratios between 1.45 and 1.75, with the best yield restricted to the range 1.5-1.6. A one-dimensional premixed flame code with a postflame heat loss model, including detailed chemistry, was used to estimate the gas phase chemical composition that favors MWCNT growth. The results of the calculations show that the mixture, including the water gas shift reaction, is not even in partial chemical equilibrium. Therefore, past discussions of compositional parameters that relate to optimum carbon nanotube (CNT) growth are revised to include chemical kinetic effects. Specifically, rapid departures of the water gas shift reaction from partial equilibrium and changes in mole fraction ratios of unburned $\mathrm{C}_{2}$ hydrocarbons to hydrogen correlate well with experimentally observed CNT yields. (c) 2006 Published by Elsevier Inc. on behalf of The Combustion Institute.
\end{abstract}

Keywords: Gas phase; Chemical kinetics; Catalyzed synthesis; Carbon nanotube; Premixed flame

\section{Introduction}

\subsection{Motivation}

Carbon nanotubes (CNTs) have found myriad applications, which include material reinforcement [1,2], mechanical actuators [3], supports for metal catalysts [4-6], battery and fuel cell applications $[7,8]$, probes/sensor applications $[9,10]$, and electronic applications $[11,12]$. CNTs are basically fullerene-related structures that consist of graphene cylin-

\footnotetext{
* Corresponding author.

E-mail address: gore@purdue.edu (J. Gore).
}

ders closed at either end with pentagonal rings. CNTs can either be single-walled carbon nanotubes (SW$\mathrm{CNT}$ ) or have a number of concentric graphene walls forming multiwalled carbon nanotubes (MWCNT).

Symmetrical geometry and highly crystalline structure enable the CNTs to possess unique electrical properties and a mechanical strength 10 times that of steel but with $1 / 6$ the weight [13]. Depending on the diameter and angle at which the graphene sheets roll (chirality) [10], the CNT can possess metallic [14,15] or semiconductor properties [16]. SWCNTs are desirable for electronic applications because of the singular chirality the tube possesses, whereas in MWCNTs each concentric tube can have a different orientation 
and chirality, making them more suited for storage and strengthening applications. Synthesis of purely single-walled CNTs is still a research frontier and control over chirality of the resulting tubes is not possible at the current state of technology. With growing commercial interest in CNTs, an economical largescale synthesis method with good control over the process is required. Flame synthesis has the advantage of being an economical and scalable alternative for commercial synthesis of CNTs [17]. To evaluate whether the potential for flame synthesis of CNTs can be fully exploited, an improved understanding of the mechanisms and controlling parameters for flame synthesis is critical. The flame environment can be economical but challenging for the design of an optimum process. The two key challenges involved are as follows: (i) the effect of surface chemistry, physical and chemical properties of the catalyst and substrate material, and their interaction with the gas phase chemistry and with each other is complicated and needs to be considered; (ii) the degree of freedom imposed by between 300 and 1000 carbon-containing species active at various pressures and temperatures makes the system complicated.

The objective of this study is to experimentally and computationally investigate the gas phase compositions that lead to CNT growth. While their fundamental and applied importance is recognized, as a first step, the substrate and the catalyst properties will be maintained fixed in this work, in order to improve our understanding of the gas phase effects.

\subsection{Current state of the science}

Both SWCNTs and MWCNTs have been grown in diffusion flames [17-20] as well as rich premixed flames. Diffusion flames have a tendency to produce MWCNTs [18-20], whereas recent work shows that premixed flames produce SWCNTs. SWCNTs have been grown in ethylene/air, acetylene/air, ethane/air [21,22], and acetylene/argon/oxygen [23] premixed flames. Van der Wal et al. [22] state that premixed flames provide a number of advantages over diffusion flames for SWCNT growth. It is seen that diffusion flame structures are a mixture of low-value materials such as soot and high-value materials such as CNTs. CNT formation in diffusion flames has been described as a follow-on to soot precursor formation [19]. Near fields of diffusion flames and rich premixed flames produce conditions under which CNTs can be formed without producing soot. These conditions are of the greatest interest here. We have selected rich premixed flames for our study because they allow better control of equivalence ratio compared to near-field diffusion flames. In the present work, we expose thinfilm cobalt catalysts supported on stainless steel grids to postcombustion gases from rich ethylene/air premixed flames.

CNT growth in the post-rich-flame environment occurs in the presence of a very large number of gas phase species including reactant species such as fuel, oxygen, and nitrogen $\left(\mathrm{N}_{2}\right)$, product species such as carbon dioxide $\left(\mathrm{CO}_{2}\right)$, carbon monoxide $(\mathrm{CO})$, water vapor $\left(\mathrm{H}_{2} \mathrm{O}\right)$, and hydrogen $\left(\mathrm{H}_{2}\right)$, intermediate species, and $\mathrm{C}_{2}$ unburnt hydrocarbons (UBHCs) such as acetylene $\left(\mathrm{C}_{2} \mathrm{H}_{2}\right)$, ethylene $\left(\mathrm{C}_{2} \mathrm{H}_{4}\right)$, and ethane $\left(\mathrm{C}_{2} \mathrm{H}_{6}\right)$, as well as higher carbon species. However, the primary indicator species for maximizing CNT initiation and growth in premixed flames have not been clearly identified. Merchan-Merchan et al. [19] performed chemical kinetic calculations for an opposed diffusion flame and related the gas phase chemistry causing CNT growth indirectly to that involved in the formation of soot. They proposed that ordered nanopolyhedral particles were a derivative of cooled soot and MWCNT growth is the result of elongation of these partially carbonized nanopolyhedral particles. Van der Wal et al. [21,22], Van der Wal [23], and Height et al. [24] correlated the yield variation of SWCNTs with equivalence ratios and have identified a maximum CNT yield equivalence ratio window for various fuel-air premixed flames. Height et al. [24] have recognized carbon monoxide as the primary source of carbon for CNT formation. A study correlating the chemical composition of the post-premixedflame gas phase mixture to CNT yield was published by Van der Wal et al. [22] and Van der Wal [23]. The authors interpreted the yield based on chemical equilibrium computations and invoked concentrations of $\mathrm{CO}$ and $\mathrm{H}_{2}$ as indicators of CNT yield through catalyst activity mechanisms [21-23].

As a first step, to identify gas phase indicator species and to investigate if CNT (MWCNT in the following, unless explicitly referred to as SWCNT) synthesis takes place at equivalence ratios where the water gas shift reaction is at equilibrium, we started a chemical kinetic study of the experiment performed by Van der Wal et al. [22] and Van der Wal [23]. A one-dimensional premixed flame code with a postflame heat loss model, including detailed chemistry. was used to estimate the gas phase chemical composition for CNT growth. We have also experimentally verified that the yield of resulting CNTs varies with equivalence ratio and that there exists a maximum yield equivalence ratio.

The specific objectives of the present work are to (i) check if well-graphitized CNTs can be grown in rich ethylene/air premixed flames and investigate their yield dependence on equivalence ratio, (ii) examine the gas species environment using detailed chemical kinetics calculations, including a check of the partial equilibrium assumption used in the past, 
and (iii) identify indicator species and parameters that define the CNT growth region.

\section{Experimental apparatus}

A cylindrical stainless steel (SS304) chimney, similar to the one described by Van der Wal et al. [22] and Van der Wal [23], with inner diameter and height of $5 \mathrm{~cm}$, was placed at an adjustable height above the surface of a McKenna burner. A schematic of the experimental arrangement is given in Fig. 1. The height of the chimney above the burner and the substrate position are decided based on the temperature at the substrate. A $\mathrm{N}_{2}$ coflow stream was employed to stabilize the flat flame. The air flow rate was held constant at $11.5 \mathrm{lpm}$ and the equivalence ratio $\phi$ was varied by changing the fuel flow rate.

A 2-nm thin layer of cobalt catalyst was deposited commercially, using a physical vapor deposition technique, on SS304 200 mesh standard TEM grids. All the grids were placed on a planetary holder system in a Leybold ion-assisted E-beam deposition machine

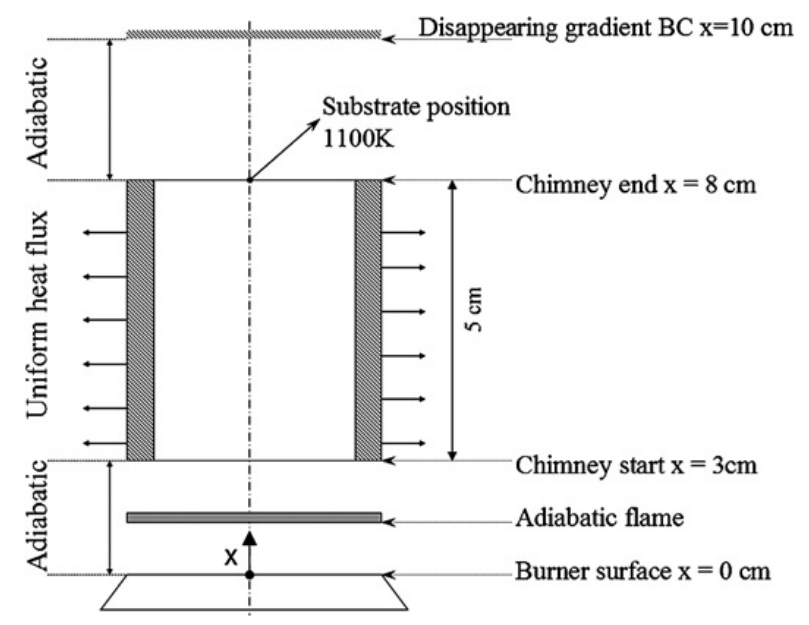

Fig. 1. Schematic diagram of the experimental arrangement and the computational heat loss model used for the chemical kinetic calculations.

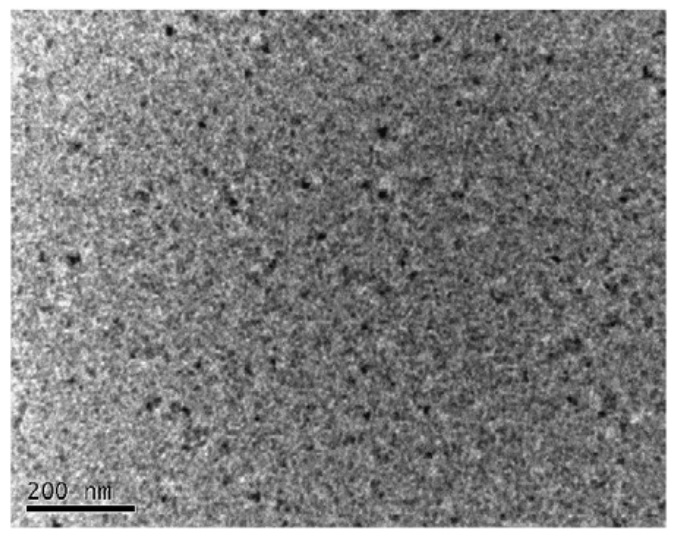

in a single batch. The deposition thickness was computer controlled by a feedback loop consisting of a quartz-crystal-oscillator-type film thickness monitor that can measure a minimum film thickness of $0.5 \mathrm{~nm}$ to an accuracy of $5 \%$. The planetary mounting system ensures uniform coating on all the grids. The target used was a $99.99 \%$ pure cobalt target. TEM-EDX analysis was performed to confirm that the deposition was cobalt. Fig. 2 shows bright field and dark field TEM images of the cobalt coating. The cobalt grains appear as dark spots for the bright field image, and they appear as bright spots for the dark field image. The density of the bright spots from the dark field image indicates that the deposition resulted in a continuous thin film of cobalt rather than disconnected island-like particles. The average grain size, as seen in the bright field image, is in the 5-nm range.

The catalyst-coated grid was held in a molybdenum mesh holder at an adjustable height above the burner surface, based on the temperature of the substrate. The cobalt deposited surface formed a stagnation layer with the incoming hydrocarbon-rich postcombustion flame gases. The gas phase temperature and substrate temperature were measured using a $0.0025-\mathrm{cm}$ R-type thermocouple and found to be within $10 \mathrm{~K}$ of each other at $1100 \mathrm{~K}$ under steady state conditions. For an equivalence ratio of 1.6, the steady state temperature at the substrate height was $1100 \mathrm{~K}$. The effect of variation in equivalence ratio on the substrate temperature was found to be negligible [21-23]. The fuel used was a commercial purity grade of $\mathrm{C}_{2} \mathrm{H}_{4}$ metered through a calibrated choked nozzle and mixed with a flow of air, also metered with a calibrated choked nozzle. The mixture flowed through at least 200 diameters before being admitted into the burner, ensuring fully premixed conditions.

\section{Computational method}

A one-dimensional premixed flame code with a postflame heat loss model, including detailed chem-

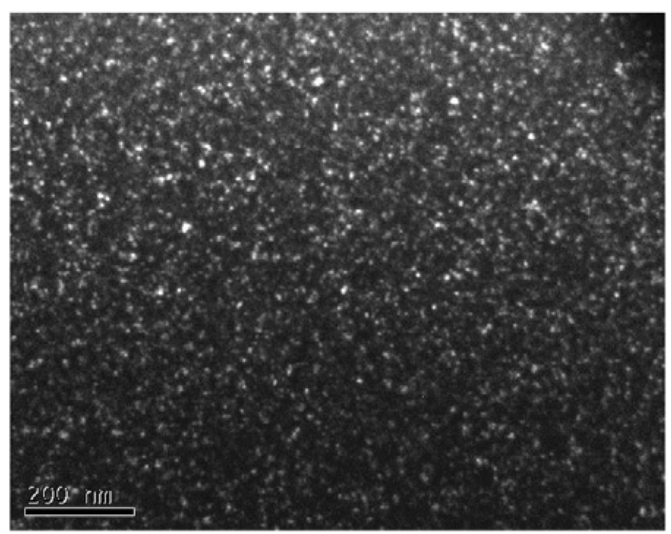

Fig. 2. A bright field TEM image of the cobalt-coated grid (left); a dark field TEM image of the cobalt-coated grid (right). 
istry, was used to estimate the gas phase chemical compositions in the region of interest. The onedimensional premixed flame code used in the work was developed at Sandia National Laboratory and is widely available as PREMIX [25]. The present heat loss model treated the convective transfer to the chimney wall as a sink term in the one-dimensional energy conservation equation. The thermophysical properties from the Chemkin database were used [26-28]. Detailed chemical kinetics from the Wang and Frenklach mechanism [29] GRIMech website (GRIMech $2.11,3.0)$ were used. The computations were performed as a grid of varying nodes based on an absolute convergence criterion for the Newton iteration set at $1 \times 10^{-9}$ and a relative convergence criterion of $1 \times 10^{-4}$. Interestingly, for the same convergence criteria, we needed 424 nodes for GRIMech 2.11 and 221 nodes for GRIMech 3.0, with downstream boundary conditions specified as gradient-free. Calculations for a range of equivalence ratios for $\mathrm{C}_{2} \mathrm{H}_{4}$ /air flames were performed.

Fig. 1 shows a schematic of the computational model. The mixture of fuel and air enters through the burner surface at the bottom $(x=0 \mathrm{~cm})$. The region outside the chimney height is assumed to be adiabatic; the chimney heat loss term is activated in the energy equation at a height of 3 to $8 \mathrm{~cm}$. The temperature at the substrate height $(8 \mathrm{~cm})$ is defined to be $1100 \mathrm{~K}$, based on experimental measurements [21-23]. A uniform heat transfer coefficient is accordingly selected to achieve this. The overall energy and species conservation are verified by comparing the residue with the lowest term in the conservation equations. In each case the residue was found to be less than $0.1 \%$ of the lowest term.

\section{Results}

\subsection{TEM images}

Figs. 3 and 4 show transmission electron microscope (TEM) images of the grid-supported catalyst exposed to varying equivalence ratios. For selected equivalence ratios, we have shown images from different locations on the grid. All other equivalence ratio images presented are typical images and not the result of spatial variation in yield. The variation in CNT yield with equivalence ratio is continuous; the images shown here are selected from a larger sample of 206 images and represent the equivalence ratios at which the most drastic changes in CNT yield are observed. In the discussion that follows, we will refer to a range of equivalence ratios rather than distinct values.

Fig. 3 (top left panel) shows that the surface of the grid remains barren of CNTs for an equivalence ra- tio of 1.44. This observation is consistent for lower equivalence ratios as well. The top right image shows a drastic increase in the yield of CNTs at an equivalence ratio of 1.47. At this equivalence ratio, the CNT yield is not uniformly distributed and there is a substantial spatial variation in the yield, as illustrated by the middle panel (left and right) images. This pattern continues for a range of $\phi$ up to 1.5. The bottom panel (left and right) shows the CNT yield for an equivalence ratio of 1.55 . The CNTs reach a maximum yield at this equivalence ratio and are uniform throughout the grid. This abundant CNT yield is typical for the equivalence ratio range between 1.5 and 1.6. The diameter distribution of resulting CNTs was from 16 to $20 \mathrm{~nm}$; the CNTs were mostly encapsulated. There were occasional nanofibers of greater diameter, reaching up to $60 \mathrm{~nm}$.

Fig. 4 (top left and right panels) show a drastic reduction in yield at $\phi=1.62$. The fall in yield continues till 1.75, after which non-CNT structures of lower yield are observed. Fig. 4 (middle left panel) shows a typical image for $\phi=1.82$ and the middle right panel shows a typical image for $\phi=1.91$.

The morphology of the resulting CNTs in the optimum CNT-yielding window of $1.5<\Phi<1.6$ is predominantly multiwalled. Fig. 4 (bottom left panel) shows a medium magnification image of the CNTs. The diameter distribution is narrow and there are few nanofibers observed. The image in the bottom right panel is a high-resolution TEM image of a closed-end CNT for $\phi=1.55$. The well-graphitized structure is evident from this image.

We confirmed that CNTs can be grown in the postcombustion environment of a rich premixed ethylene/air flame. We also confirmed that there exists a relationship between the yield of resulting CNTs and the equivalence ratio of the fuel/air mixture. It was observed that, for the range $1.5<\phi<1.6$, the maximum yield and best morphology CNTs were produced. For a richer equivalence ratio $(1.62<\phi<$ 1.75), the yield of CNTs fell substantially. For a leaner equivalence ratio $(1.47<\phi<1.49)$, the yield of CNTs was less than the maximum yield range, even for longer residence times. For $\phi<1.45$, no CNTs were observed to grow. For $\phi>1.75$, nonCNT structures of low yield are predominant. The effect of changing equivalence ratios on CNT yield is interpreted, based on gas phase chemistry, using chemical kinetics computations. The discussion of the gas phase composition changes that correspond to this drastic change in the yield follows.

\subsection{Gas phase composition}

The chemical kinetics computation results are presented in Figs. 5-7. Fig. 5 (top and middle panels) 

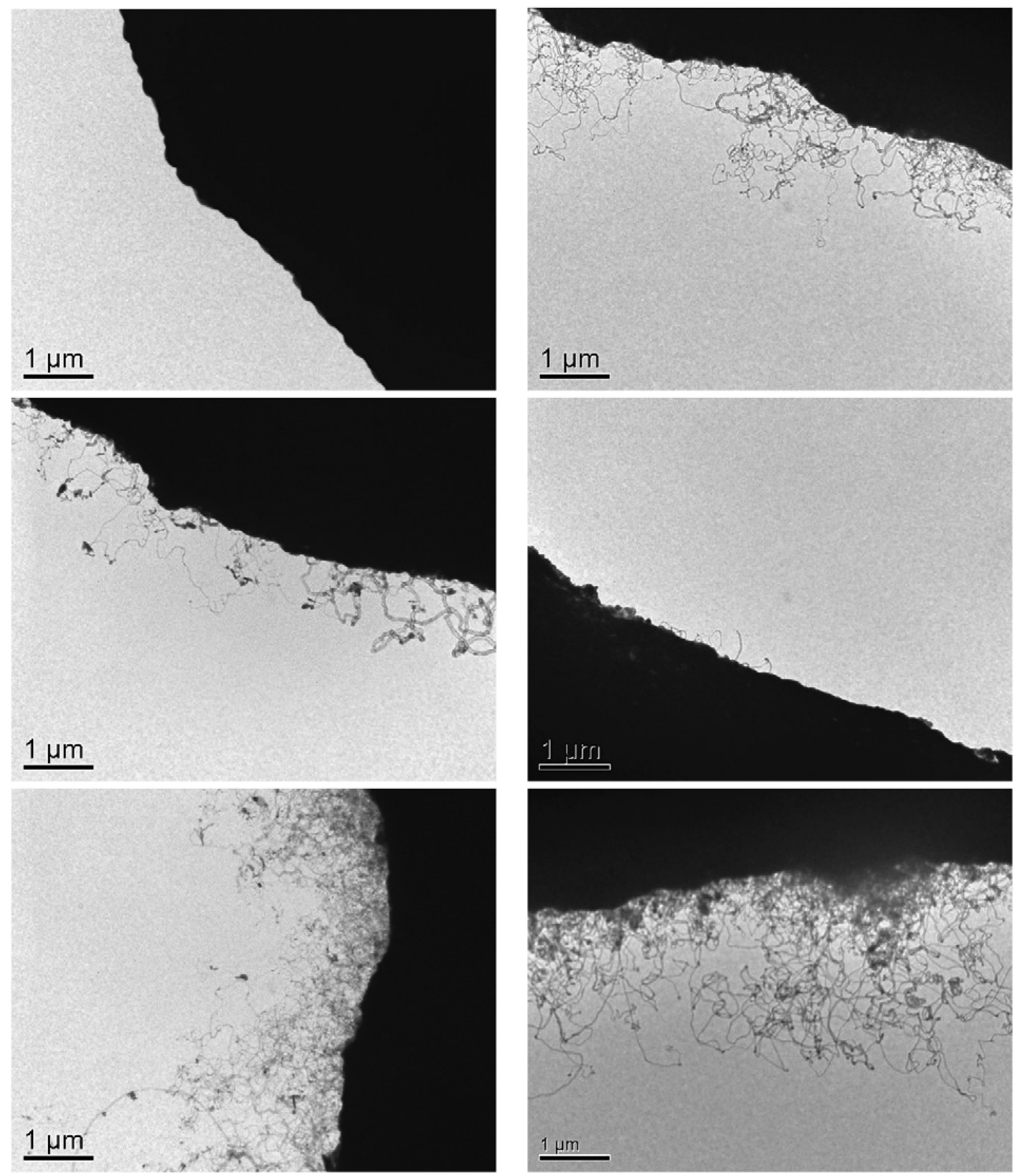

Fig. 3. Typical TEM image of MWCNTs for $\mathrm{C}_{2} \mathrm{H}_{4}$ /air premixed flame: $\phi=1.44$ (top left), $\phi=1.47$ (top right and middle panels), and $\phi=1.55$ (bottom panels).

shows the variation of mole fraction of major gas species and temperature with distance from the burner surface for an equivalence ratio of 1.6. The bottom panel shows the variation of the minor $C_{2}$ species. The distance is plotted on a logarithmic scale to depict the relatively thin flame region in which the temperature and species concentrations undergo very large changes, followed by the heat loss region in which the changes in all quantities are small. The temperature reaches an adiabatic value of $2133 \mathrm{~K}$ at $0.25 \mathrm{~cm}$ from the burner surface, following a rapid increase in the flame region between 0.06 and $0.25 \mathrm{~cm}$. The fuel and oxygen mole fractions deplete completely in this region, at the resolution of the top panel. The nitrogen mole fractions decrease in the flame region because of the increase in the total number of moles as a result of the combustion reactions. In the heat loss region between 3 and $8 \mathrm{~cm}$ (seen in the right $1 / 4$ width of Fig. 5), the temperature decreases from 2133 to $1100 \mathrm{~K}$. However, there are no perceptible changes in the major gas species mole fractions at the resolution of the top panel. The middle panel shows the rapid growth in $\mathrm{H}_{2}, \mathrm{CO}$, and $\mathrm{H}_{2} \mathrm{O}$ in the early part of the flame and the somewhat slower but still (before $0.25 \mathrm{~cm}$ ) increasing mole fraction of $\mathrm{CO}_{2}$. By $0.25 \mathrm{~cm}$ above the burner surface, these species also reach their approximately constant postflame values. The preferential diffusion of $\mathrm{H}_{2}$ toward the upstream region can be clearly observed in the middle panel. The bottom panel shows that the $\mathrm{C}_{2}$ hydrocarbon species increase to their maximum value in the preflame region. However, both $\mathrm{C}_{2} \mathrm{H}_{2}$ and $\mathrm{C}_{2} \mathrm{H}_{6}$ con- 

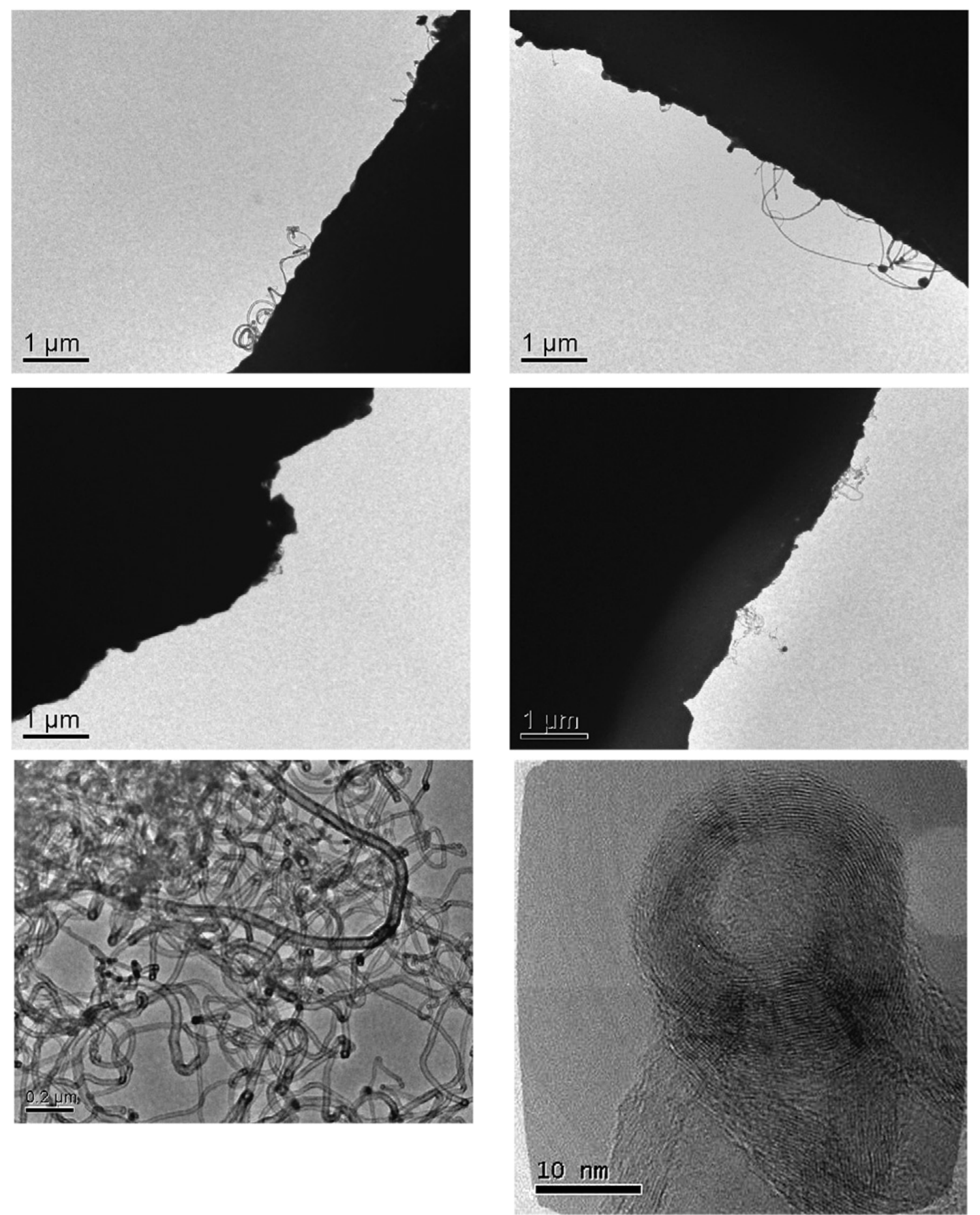

Fig. 4. Low-magnification TEM images showing low-yield, non-CNT structures: (top panels) $\phi=1.62$, (middle left) $\phi=1.82$, (middle right) $\phi=1.91$, (bottom left) medium magnification, and (bottom right) high-resolution images of CNTs for best yield equivalence ratio of 1.55 .

tinue to react in the relatively constant-temperature postflame region and decline by close to 10 orders of magnitude in the distance between $0.08 \mathrm{~cm}$, where these species reach a peak, and $3 \mathrm{~cm}$, where the heat loss begins. At a height of $8 \mathrm{~cm}$ from the burner surface, the temperature of the gas mixture is $1100 \mathrm{~K}$ and the concentration of $\mathrm{C}_{2} \mathrm{H}_{2}$ is greater than those of $\mathrm{C}_{2} \mathrm{H}_{4}$ and $\mathrm{C}_{2} \mathrm{H}_{6}$ as seen from the last $1 / 4$ width of the bottom panel.

Fig. 6 shows the temperature, the mole fractions of the participant gases in the water gas shift reaction, and the mole fractions of the $\mathrm{C}_{2}$ hydrocarbon species plotted as a function of distance from the burner in the postflame heat loss region on a linear scale. The water gas shift reactions (top panel) commence with the heat loss and start moving the composition toward the equilibrium values at lower temperatures. The $\mathrm{CO}$ and $\mathrm{H}_{2} \mathrm{O}$ concentrations decrease slightly and the $\mathrm{CO}_{2}$ and $\mathrm{H}_{2}$ concentrations correspondingly increase. $\mathrm{H}_{2}$ reactions at the surface are known to reactivate catalyst sites by the removal of excess carbon in soot growth models [29-31]. It is possible that $\mathrm{H}_{2}$ reac- 


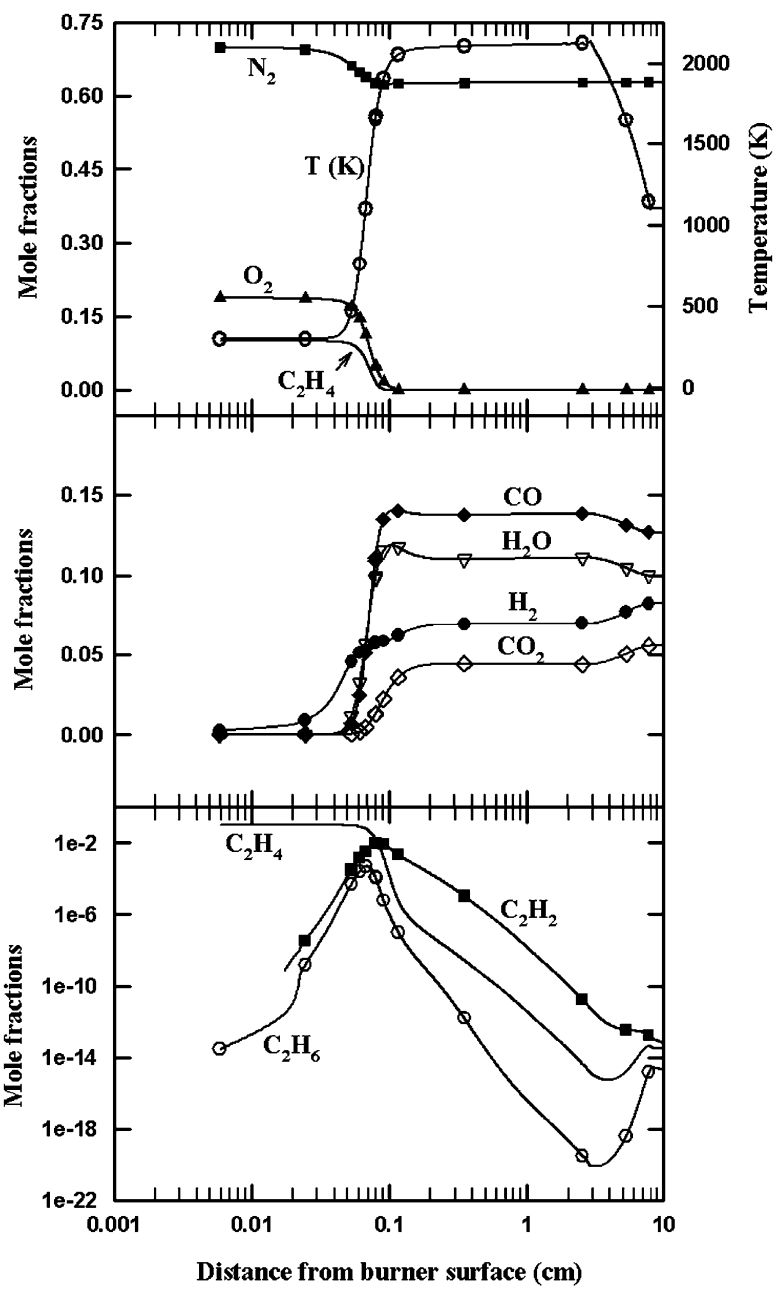

Fig. 5. Variation in computed mole fractions of major and minor combustion species and temperature of the gas mixture with distance from burner surface plotted on a logarithmic scale: (top) the mole fractions of major gas species and temperature; (middle) the variation in the water gas shift reaction species; (bottom) the variation of minor $\mathrm{C}_{2}$ hydrocarbon species with distance from the burner surface.

tions at the catalyst surface can play a similar role during the inception and growth of CNTs in nonsooting flames. The unburned hydrocarbon (bottom three panels) oxidation quenches and the unburned hydrocarbon mole fractions increase slightly as a result of the reduction in temperature. It is observed that the $\mathrm{C}_{2}$ hydrocarbons $\left(\mathrm{C}_{2} \mathrm{H}_{2}\right.$ in the second from the bottom and $\mathrm{C}_{2} \mathrm{H}_{4}, \mathrm{C}_{2} \mathrm{H}_{6}$ from the bottom panels) reach a maximum value in the temperature range in which CNTs are observed to grow.

Fig. 7 (top panel) depicts the calculated mole fractions at a height representing a temperature of $1100 \mathrm{~K}$ (representatively selected for CNT synthesis) of the species involved in the water gas shift reaction, plotted as a function of equivalence ratio. There is an increase in mole fractions of $\mathrm{CO}$ and $\mathrm{H}_{2}$ and a simultaneous reduction in the mole fraction of $\mathrm{H}_{2} \mathrm{O}$ with increasing equivalence ratio. This pattern is consistent irrespective of the chemical mechanism employed,

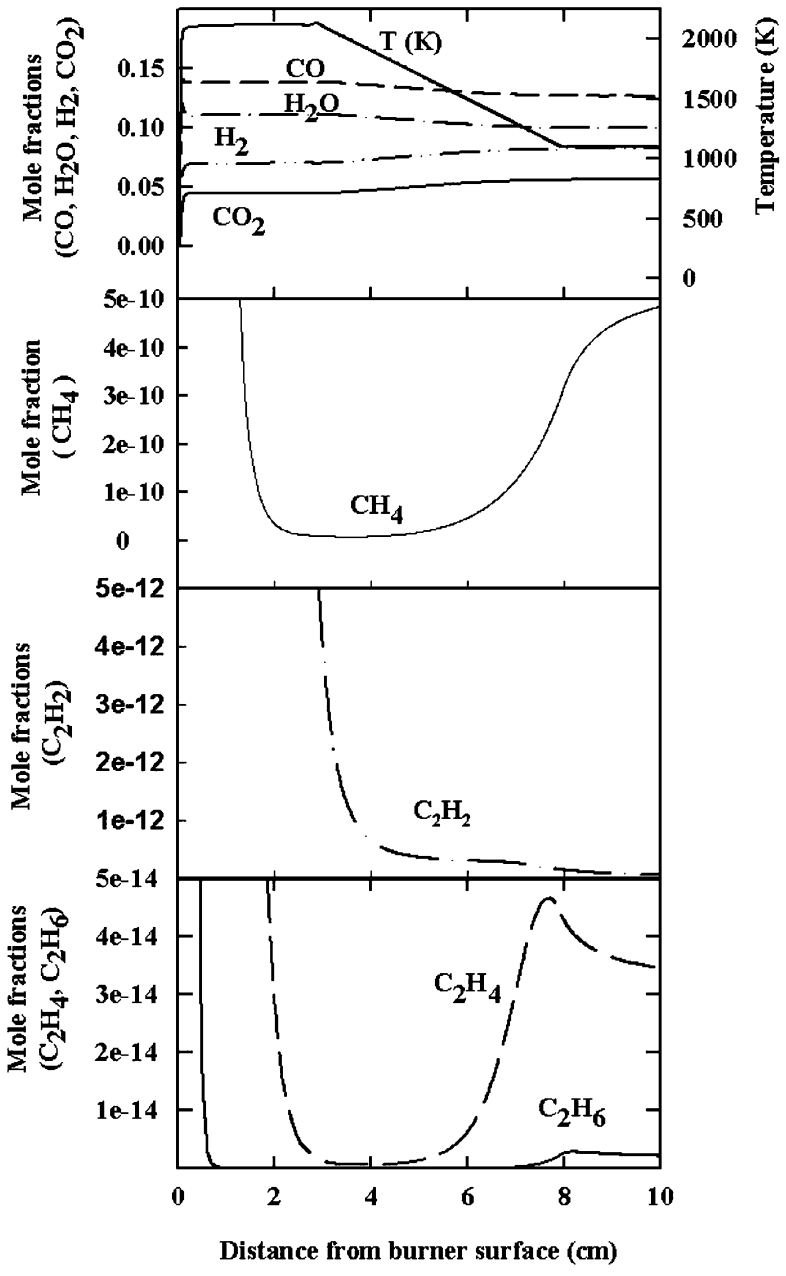

Fig. 6. Spatial variation in (top) computed temperature, (top) mole fractions of water gas species, and (bottom three) $\mathrm{CH}_{4}$ and minor $\mathrm{C}_{2}$ hydrocarbon species in the heat loss region plotted against a linear scale to highlight the chemical activity in the heat loss region.

as indicated in the legend as 2.11 (GRIMech 2.11), 3.0 (GRIMech 3.0), and WF (Wang and Frenklach). Both $\mathrm{H}_{2}$ and $\mathrm{H}_{2} \mathrm{O}$ are powerful reducing agents on transition metal surfaces. At an equivalence ratio of 1.5 , the relative ratio of $\mathrm{CO}$ and $\mathrm{H}_{2} \mathrm{O}$ reaches unity. The higher levels of $\mathrm{H}_{2}$ are conducive to activation of the catalyst surface and help define the CNT inception and growth equivalence ratios. The ratios of mole fractions of $\mathrm{CO}$ and $\mathrm{H}_{2}$, and $\mathrm{CO}_{2}$ and $\mathrm{H}_{2} \mathrm{O}$, and a ratio of these two ratios $\left([\mathrm{CO}]\left[\mathrm{H}_{2} \mathrm{O}\right]\right) /\left(\left[\mathrm{CO}_{2}\right]\left[\mathrm{H}_{2}\right]\right)$, as well as $K_{\mathrm{p}}$, are depicted in the middle panel of Fig. 7. The quantity $\left([\mathrm{CO}]\left[\mathrm{H}_{2} \mathrm{O}\right]\right) /\left(\left[\mathrm{CO}_{2}\right]\left[\mathrm{H}_{2}\right]\right)$ would have been equal to $K_{\mathrm{p}}$ under partial equilibrium of the water gas shift reaction conditions. The difference between these quantities observed in Fig. 7 illustrates the departure from equilibrium. Both $\mathrm{CO}$ and $\mathrm{CO}_{2}$ decrease relative to $\mathrm{H}_{2}$ and $\mathrm{H}_{2} \mathrm{O}$ as the equivalence ratio increases toward the optimum CNT-forming equivalence ratio. By comparing the $K_{\mathrm{p}}$ plot and the plot of mole fraction ratios $\left([\mathrm{CO}]\left[\mathrm{H}_{2} \mathrm{O}\right]\right) /\left(\left[\mathrm{CO}_{2}\right]\left[\mathrm{H}_{2}\right]\right)$, it is clear that the actual composition is far from that 


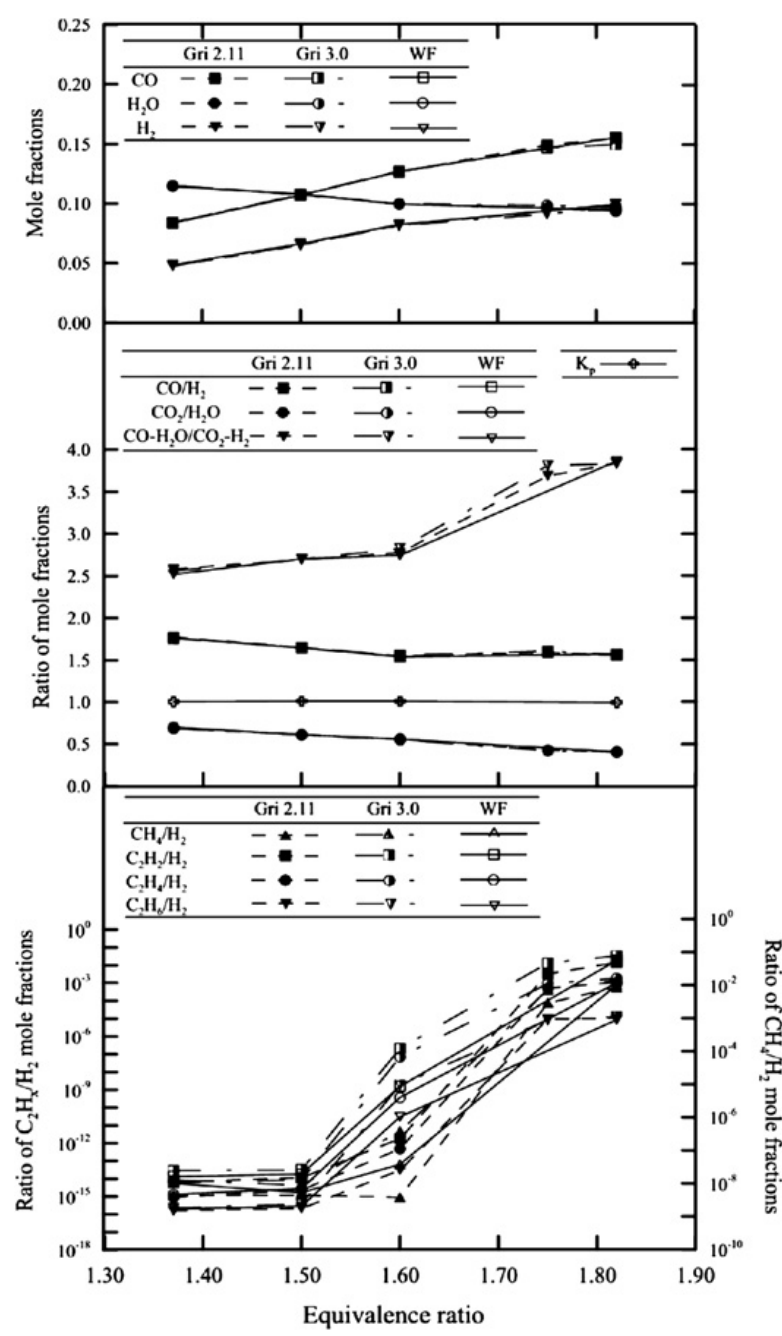

Fig. 7. Variation of (top) mole fractions of $\mathrm{H}_{2}$ and $\mathrm{H}_{2} \mathrm{O}$ with $\Phi$; (middle) $\mathrm{CO} / \mathrm{H}_{2}, \mathrm{CO}_{2} / \mathrm{H}_{2} \mathrm{O},\left([\mathrm{CO}]\left[\mathrm{H}_{2} \mathrm{O}\right] /\left[\mathrm{H}_{2}\right]\right.$ $\left.\left[\mathrm{CO}_{2}\right]\right)$, and the equilibrium constant $\left(K_{\mathrm{p}}\right)$ for the water gas shift reaction with $\Phi$; (bottom) the ratios of mole fractions of $\mathrm{CH}_{4}$ and main $\mathrm{C}_{2}$ hydrocarbons to $\mathrm{H}_{2}$ as a function of $\phi$.

required for partial equilibrium for the water gas reaction. The dashed (GRI 2.11), solid (GRI 3.0), and dash-dot (WF) lines illustrate that this departure from partial equilibrium is independent of the mechanism used. The bottom panel of Fig. 7 shows $\mathrm{CH}_{4}$ mole fractions and $\mathrm{C}_{2}$ hydrocarbon species mole fractions divided by the hydrogen mole fractions, as a function of the equivalence ratio. As has been noted in the past, GRIMech 2.11, 3.0, and WF predict very different $\mathrm{C}_{2}$ species concentrations. These differences lead to a variation in the rate at which the ratios of $\mathrm{CH}_{4}$ and $\mathrm{C}_{2}$ species concentrations to $\mathrm{H}_{2}$ concentration increase in the range of the $\mathrm{CNT}$ growth equivalence ratios. However, both mechanisms show a significant increase in the $\mathrm{CH}_{4}$ and $\mathrm{C}_{2}$ hydrocarbons relative to hydrogen in the equivalence ratio range from 1.5 to 1.7. The growth in $\mathrm{C}_{2}$ hydrocarbon species relative to hydrogen is more pronounced in the 1.5 to 1.6 region.

\section{Discussion}

The experimental results indicate drastic CNT yield variation with equivalence ratio. However, CNTs are formed in very small amounts even at their highest yield. Therefore, it is very difficult to relate the quantitative changes in any gaseous species directly to the CNT yield. Hence, we consider the trends in both the major and minor species compositions in the relevant equivalence ratio range. There is a very significant rise of up to 10 orders of magnitude of $\mathrm{C}_{2}$ hydrocarbons and up to 6 orders of magnitude of $\mathrm{CH}_{4}$ relative to hydrogen mole fraction near the maximum yield equivalence ratio. These observations suggest that the variation in CNT yield is qualitatively similar to the variation in the relative mole fractions of hydrocarbons and hydrogen. Both these variations occur simultaneously with significant departures from equilibrium. On the other hand, the changes in $\mathrm{CO}$ and $\mathrm{H}_{2}$ concentrations with equivalence ratio are continuous and monotonic.

$\mathrm{CO}$ can be the source of carbon via two known mechanisms, the Boudouard reaction and the hydrogenation reaction. $\mathrm{CO}$ is a stable compound and requires up to $5 \mathrm{eV}$ of energy to initiate its disproportionation (Boudouard reaction) [32-34]. CO has been used as the primary source of carbon for CNT synthesis in other manufacturing processes [35,36]. Many of these methods require either high pressures or an external source of energy to initiate this reaction. At the low temperatures and atmospheric pressures involved in flame synthesis of CNTs, further research into the exact mechanism involved in the conversion of $\mathrm{CO}$ to a catalyst-blocking species [22] or a CNT-forming species $[22,23]$ is required.

Our experimental results show that there is a drop in CNT yield above an $\Phi$ of 1.6 (Figs. 3 and 4); this is also consistent with other premixed flame experiments performed with the same fuel-air combination [21-23]. This can be explained in terms of the steep increase in $\mathrm{C}_{2}$ hydrocarbons in the postcombustion gases that react with the catalyst and undergo graphitization [37] to produce surface carbon. When the rate of production of surface carbon (either through the graphitization of hydrocarbons or the disproportionation and hydrogenation of carbon monoxide) is greater than the diffusion rate of this surface carbon into the catalyst particle, the active surface area of the catalyst sites get deactivated. To some extent, species such as hydrogen can reduce the surface carbon (which can be both graphitic and amorphous in form) in a manner similar to the reactivation of catalyst sites in soot growth models [29-31]. However, the gradient of change in mole fraction of hydrogen is not comparable to that of the $\mathrm{C}_{2}$ hydrocarbons, and as a result the catalyst sites get deactivated and the CNT yield falls. 


\section{Conclusions}

Multiwalled carbon nanotubes are grown in rich premixed $\mathrm{C}_{2} \mathrm{H}_{4}$ /air flames. It is observed that the yield of MWCNTs varies with the equivalence ratio of the fuel-air mixture. Chemical kinetics calculations show that the gas phase mixture leading to CNT growth is not in partial equilibrium even for the water gas shift reaction. Therefore, equilibrium composition should not be used to develop CNT growth theories. The existing equilibrium-based theory for optimum CNT yield is revised.

There are mild variations in major and minor species mole fractions depending on the mechanism selection; this mechanism effect needs to be addressed. However, the conclusions based on the chemical kinetic calculations are independent of the chemical mechanism employed. Namely, rapid departures from the partial equilibrium of the water gas shift reaction and rapid changes in mole fraction ratios of $\mathrm{C}_{2}$ unburned hydrocarbon to $\mathrm{H}_{2}$ with equivalence ratio strongly correlate with the experimentally observed range of equivalence ratios over CNT yield increase. From the chemical kinetics results, $\mathrm{C}_{2}$ hydrocarbon species mole fractions divided by hydrogen mole fractions increase by 10 orders of magnitude as the equivalence ratios corresponding to high CNT yield are approached.

\section{Acknowledgments}

The authors gratefully acknowledge Dr. Randy L. Van der Wal, from the National Center for Microgravity Research, NASA Glenn Research Center, for his useful suggestions.

\section{References}

[1] C. Bower, R. Rosen, L. Jin, J. Han, O. Zhou, Appl. Phys. Lett. 74 (1999) 3317.

[2] G. Overney, W. Zhong, D. Tomanek, J. Phys. D 27 (1993) 93.

[3] B.J. Landi, R.P. Rafaell, M.J. Heben, J.L. Allenman, W. Van Deveer, T. Gennett, Nano Lett. 2 (11) (2002) 1329-1332.

[4] http://www.grc.nasa.gov/WWW/RT2000/6000/ 6711 vanderwal.html.

[5] N. Rodriquez, M. Kim, R. Baker, J. Phys. Chem. 98 (1994) 13108.

[6] B. Gao, A. Kleinhammes, X. Tang, C. Bower, L. Fleming, Y. Wu, O. Zhou, Chem. Phys. Lett. 307 (1999) 153.

[7] A. Dillon, K. Jones, T. Bekkendahl, C. Kiang, D. Bethune, M. Heben, Nature 386 (1997) 377.

[8] J. Kong, N. Franklin, C. Zhou, M. Chapline, S. Peng, K. Cho, H. Dai, Science 287 (2000) 622-625.

[9] A. Rinzler, J. Hafner, P. Nikolaev, L. Lou, S. Kim, D. Tomanek, P. Nordlander, D. Colbert, R. Smalley, Science 269 (1995) 1550-1553.
[10] R. Saito, G. Dresselhaus, M. Dresselhaus, Physical Properties of Carbon Nanotubes, Imperial College Press, 1998, p. 35.

[11] P. Collins, M. Arnold, P. Avouris, Science 292 (2001) 706.

[12] P. Avouris, Chem. Phys. 281 (2002) 429-445.

[13] S. Yoshimura, R. Chang, Supercarbon-Synthesis, Properties and Applications, Springer, 1998, p. 22.

[14] J. Mintmire, B. Dunlap, C. White, Phys. Rev. Lett. 68 (1992) 631.

[15] N. Hamada, S. Sawada, A. Oshiyama, Phys. Rev. Lett. 68 (1992) 1579.

[16] R. Saito, M. Fujita, G. Dresselhaus, M. Dresselhaus, Phys. Rev. B 46 (1992) 1804.

[17] R. Van der Wal, T. Icich, V. Curtis, Chem. Phys. Lett. 323 (2000) 217-223.

[18] L. Yuan, K. Saito, W. Hu, Z. Chen, Chem. Phys. Lett. 346 (2001) 23-28.

[19] W. Merchan-Merchan, A.V. Saveliev, L.A. Kennedy, Combust. Sci Technol. 175 (2003) 2217-2236.

[20] L. Yuan, T. Li, K. Saito, Carbon 41 (2002) 1889-1896.

[21] R. Van der Wal, L. Hall, G. Berger, Proc. Combust. Inst. 29 (2002) 1079-1085.

[22] R. Van der Wal, L. Hall, G. Berger, J. Phys. Chem. B 106 (2002) 13122-13132.

[23] R. Van der Wal, Combust. Flame 130 (1) (2002) 37-47.

[24] M. Height, J.B. Howard, J.W. Tester, J.B. Van der Sande, Carbon 42 (2004) 2295-2307.

[25] R. Kee, J. Grcar, M. Smooke, J. Miller, Sandia Report: A Fortran Program for Modeling Steady Laminar OneDimensional Premixed Flames, SAND85-8240, Sandia National Laboratories, October 1990.

[26] R.J. Kee, F.M. Rupley, J.A. Miller, The Chemkin Thermodynamic Database, SAND87-8251B, Sandia National Laboratories, 1992.

[27] R.J. Kee, G. Dixon-Lewis, J. Warnatz, M.E. Coltrin, J.A. Miller, A Fortran Computer Code Package for the Evaluation of Gas-Phase Multicomponent Transport Properties, SAND86-8246, Sandia National Laboratories, 1991.

[28] R.J. Kee, F.M. Rupley, J.A. Miller, Chemkin-II: A Fortran Chemical Kinetics Package for the Analysis of Gas-Phase Chemical Kinetics, SAND89-8009B, Sandia National Laboratories, 1995.

[29] http://www.me.berkeley.edu/soot/mechanisms/wf.html.

[30] M. Frenklach, H. Wang, M.J. Rabinowitz, Prog. Energy Combust. Sci. 18 (1992) 47.

[31] M. Frenklach, H. Wang, Proc. Combust. Inst. 23 (1990) 1559.

[32] H. Cheng, D.B. Reiser, D. Dean Jr., Catal. Today 50 (1999) 579-588.

[33] E. Plonjes, P. Palm, G.B. Viswanathan, V.V. Subramaniam, I.A. Adomovich, W.R. Lempert, H.L. Fraser, J.W. Rich, Chem. Phys. Lett. 352 (2002) 342-347.

[34] A. Moisala, A.G. Nasibulin, E.I. Kauppinen, J. Phys. Condens. Matter 15 (2003) S3011-S3035.

[35] H. Dai, A. Rinzler, P. Nikolaev, A. Thess, D. Colbert, R. Smalley, Chem. Phys. Lett. 260 (2001) 471-475.

[36] Alvarez, F. Pompeo, J. Herrera, L. Balzano, D. Resasco, Chem. Mater. 14 (2002) 1853-1858.

[37] H. Marsh, A. Waburton, J. Appl. Chem. 20 (1970) 133. 